\title{
Long-term effects of fine particulate matter exposure on the progression of arterial stiffness
}

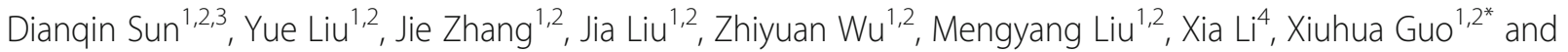
Lixin $\operatorname{TaO}^{1,2^{*}}$ (D)

\begin{abstract}
Background: Prior studies have investigated the association of $\mathrm{PM}_{2.5}$ exposure with arterial stiffness measured by ankle-brachial index (ABI) and brachial-ankle pulse wave velocity (baPWV), of which conclusions are inconsistent. Moreover, limited evidence is available on the contributory role of $\mathrm{PM}_{2.5}$ exposure on the arterial stiffness index.

Methods: We used the population data from the Beijing Health Management Cohort and conducted a longitudinal analysis. The annual average concentration of $\mathrm{PM}_{2.5}$ for 35 air pollutant monitoring sites in Beijing from 2014 to 2018 was used to estimate individual exposure by different interpolation methods. Multivariate logistic regression and linear regression were conducted to assess the association of annual average $\mathrm{PM}_{2.5}$ concentration with the incidence of higher baPWV, the progression of $\mathrm{ABl}$, and baPW, respectively.

Results: The association between $\mathrm{PM}_{2.5}$ exposure and incidence of higher baPWV was not significant (OR $=1.11$, 95\% Cl: $0.82-1.50, P=0.497)$. There was $-0.16 \%$ (95\% Cl: $-0.43-0.11 \%)$ decrease in ABI annually and 1.04\% (95\% Cl: $0.72-1.37 \%$ ) increase in baPWV annually with each increment of $10 \mu \mathrm{g} / \mathrm{m}^{3}$ average $\mathrm{PM}_{2.5}$ concentration.

Conclusions: Long-term exposure to $\mathrm{PM}_{2.5}$ was associated with the progression of arterial stiffness in Beijing. This study suggests that improvement of air quality may help to prevent arterial stiffness.
\end{abstract}

Keywords: Fine particulate matter, Arterial stiffness, Ankle-brachial index, Brachial-ankle pulse wave velocity

\section{Background}

Recent decades have witnessed the rapid growth of the Chinese economy, unfortunately, along with severe fine particulate matter pollution, especially in north China [1]. Fine particulate matter, known as $\mathrm{PM}_{2.5}$, has been regarded as one of the culprits in cardiovascular diseases $[2,3]$. It has been reported that increased long-term exposure to $\mathrm{PM}_{2.5}$ is associated with elevated cardiovascular morbidity and mortality [4]. The potential mechanism behind the association has become a subject of

\footnotetext{
* Correspondence: statguo@ccmu.edu.cn; taolixin@ccmu.edu.cn ${ }^{1}$ School of Public Health, Capital Medical University, Beijing 100069, China Full list of author information is available at the end of the article
}

research. The effect of $\mathrm{PM}_{2.5}$ on arterial stiffness, one of the pathways to severe cardiovascular diseases, has attracted more and more attention [5-7].

Increased arterial stiffness, a measure of vascular dysfunction, is highly relevant to the atherosclerosis process and is also seen as an independent risk factor for cardiovascular events [8]. Ankle-brachial index (ABI) and pulse wave velocity (PWV) are two sensitive markers for arterial stiffness and easy to use. ABI is measured as the ratio of systolic blood pressure at the ankle to that at the brachial artery [9]. The low $\mathrm{ABI}$ is used to diagnose peripheral artery disease in clinical practice, while the high $A B I$ may indicate non-compressible arteries and arterial calcification. PWV is the most widely used measure of

(c) The Author(s). 2021 Open Access This article is licensed under a Creative Commons Attribution 4.0 International License, which permits use, sharing, adaptation, distribution and reproduction in any medium or format, as long as you give appropriate credit to the original author(s) and the source, provide a link to the Creative Commons licence, and indicate if changes were made. The images or other third party material in this article are included in the article's Creative Commons licence, unless indicated otherwise in a credit line to the material. If material is not included in the article's Creative Commons licence and your intended use is not permitted by statutory regulation or exceeds the permitted use, you will need to obtain permission directly from the copyright holder. To view a copy of this licence, visit http://creativecommons.org/licenses/by/4.0/ The Creative Commons Public Domain Dedication waiver (http://creativecommons.org/publicdomain/zero/1.0/) applies to the data made available in this article, unless otherwise stated in a credit line to the data. 
arterial stiffness, which was calculated by dividing the distance between the arteries' two points with the corresponding pressure wave transit time. Various types of PWV measurements were applied in clinical and academic fields, among which carotid-femoral PWV (cfPWV) and brachial-ankle PWV (baPWV) are the most widely used. Brachial-ankle PWV is strongly associated with cfPWV [10], the gold standard for measuring central arterial stiffness [11], but baPWV measurement is more conveniently used and popular in Asian countries [12]. Previous studies have investigated the association of $\mathrm{PM}_{2.5}$ exposure with baPWV and ABI $[5,13-$ 15], of which conclusions are inconsistent. A crosssectional study reported the relationship between $\mathrm{PM}_{2.5}$ exposure and ABI [13], which was not observed in other studies $[14,16]$.

Furthermore, few were conducted to investigate the long-term effects in areas with relatively more severe $\mathrm{PM}_{2.5}$ pollution in China. The nonlinear relationship between air pollution and health effects may indicate that evidence from other regions may not be suitable to the population in areas with high air pollution in Beijing, China. Moreover, it was reported that racial differences might exist in air pollutants' cardiovascular effect [17].

Therefore, in this study, we used the population data from the Beijing Health Management Cohort (BHMC) and conducted a longitudinal analysis to investigate the long-term effects of $\mathrm{PM}_{2.5}$ exposure on the change of arterial stiffness markers, including $\mathrm{ABI}$ and baPWV.

\section{Methods}

\section{Study design and population}

We conducted this study using data from the BHMC, a large dynamic cohort aiming fixed working environment population in Beijing, of which design has been described in previous studies [18]. Participants in BHMC underwent a comprehensive health examination every year or every 2 years. Since our aim was to estimates the effects of $\mathrm{PM}_{2.5}$ exposure on the progression of $\mathrm{ABI}$ and baPWV, we retrieved data of participants who underwent at least two examinations of $\mathrm{ABI}$ and baPWV $(n=4789)$ during 2014-2018. The first and last measurements were used. Then those participants with abnormal $\mathrm{ABI}(\mathrm{ABI}<0.9$ or $\mathrm{ABI}>1.4)$ or baPWV (baPWV $>1800 \mathrm{~cm} / \mathrm{s}$ ) at first measurement were excluded $(n=838)$. Finally, 3951 participants were included in the study. All participants provided written informed consent. This study was approved by the Ethics Committees of Capital Medical University (approval number: 2013SY26).

\section{Measures of arterial stiffness}

$\mathrm{ABI}$ and baPWV were measured using an automatic arteriosclerosis analyzer. The $\mathrm{ABI}$ is measured as the ratio of systolic blood pressure at the ankle to that at the brachial artery. ABIs were calculated separately for both sides by the highest pressure of the ankle on the side divided by the highest brachial pressure on either side, and the minimum was used for analyses. According to previous studies [19-21], lower $A B I$, higher $A B I$ and higher baPWV was respectively defined as $\mathrm{ABI}<0.9, \mathrm{ABI}>1.4$ and $\mathrm{baPWV}>1800 \mathrm{~cm} / \mathrm{s}$. Besides, the progression of $\mathrm{ABI}$ and baPWV were assessed using the relative annual change (\%) [22], which was calculated via the equation: $\frac{\text { value at last measurement }- \text { value at first measurement }}{\text { follow - up year } \times \text { value at first measurement }}$.

\section{$\mathrm{PM}_{2.5}$ exposure assessment}

We collected daily average $\mathrm{PM}_{2.5}$ concentration data from 2014 to 2018 recorded by 35 monitoring sites from the Beijing Municipal Environmental Monitoring Center's website (http://zx.bjmemc.com.cn/). The annual average concentration in each monitoring site was calculated. The empirical Bayesian Kriging method was applied to assess individual exposure based on the workplace address using ArcGIS 10.5 software [23]. Because $\mathrm{PM}_{2.5}$ data recorded by monitors were not available before 2014, pollution data from 2012 to 2013 was gained from $\mathrm{PM}_{2.5}$ Hindcast Database. $\mathrm{PM}_{2.5}$ Hindcast Database [24] provides annual concentrations of $\mathrm{PM}_{2.5}$ in a regular grid of $0.1^{\circ} \times 0.1^{\circ}$, developed and maintained by Tsinghua university based on Moderate Resolution Imaging Spectroradiometer (MODIS) satellite aerosol datasets. In addition, we also used the Inverse Distance Weighting (IDW) interpolation method and data from the nearest monitoring site to estimate individual exposure in the sensitivity analysis. According to prior studies $[25,26]$, the average value $\left(\mu \mathrm{g} / \mathrm{m}^{3}\right)$ from the baseline year to the last visit year was used as the estimated exposure. Because $\mathrm{PM}_{2.5}$ data from 2014 to 2016 were also available in $\mathrm{PM}_{2.5}$ Hindcast Database, we could conduct linear regression to test the correlation between data from $\mathrm{PM}_{2.5}$ Hindcast Database and those calculated based on records from monitoring sites during 2014 to 2016. The results indicated that data in $\mathrm{PM}_{2.5}$ Hindcast Database were strongly correlated with the estimates of the IDW interpolation method (Supplementary Table S1). However, data by the empirical Bayesian Kriging method tended to be higher, and data from the nearest monitoring site tended to be lower than estimates in $\mathrm{PM}_{2.5}$ Hindcast Database.

\section{Covariates assessment}

In BHMC, trained medical personnel conducted the physical examination. Height and weight were measured, and body mass index (BMI) was calculated according to the formula: $\mathrm{BMI}=\frac{\text { Weight }(\mathrm{kg})}{\text { Height }(\mathrm{m})^{2}}$. Blood pressure was measured three times after participants were seated, and the 
average value was used. Fasting blood samples were collected. Triglycerides (TG), total cholesterol (TC), highdensity lipoprotein cholesterol (HDL-C), low-density lipoprotein cholesterol (LDL-C), and fasting plasma glucose (FPG) were measured by enzymatic methods using a chemistry analyzer (Beckman LX 20, Beckman, Brea, CA, USA). In this study, FPG $\geq 100 \mathrm{mg} / \mathrm{dL}$ or using anti-diabetic drugs was defined as diabetes. Hypertension was defined as elevated blood pressure (systolic BP $\geq 130 \mathrm{mmHg}$ and/or diastolic $\mathrm{BP} \geq 85 \mathrm{mmHg}$ ) or antihypertensive drug treatment. Demographic data, including age, gender, education, smoking, alcohol use, and physical activities, were collected by self-administered questionnaires. We defined smoking as currently smoking and/or having smoked at least 100 cigarettes in one's lifetime, drinking as having consumed alcohol 12 or more times in the last year. Physical activity was classified into three levels: low, moderate, and high intensity.

\section{Statistical analysis}

Characteristics of participants were described with the mean (standard deviation, SD) for continuous variables with normal distribution or median (interquartile range, IQR) for those with skewed distribution and number (percentage) for categorical variables. Baseline characteristics were compared with $t$ test, Wilcoxon rank test, or $X^{2}$ test, as appropriate. Because the number of participants with abnormal ABI incidence was too small $(n=4$ for $\mathrm{ABI}>1.4, n=14$ for $\mathrm{ABI}<0.9$ ), we did not investigate the association of annual average $\mathrm{PM}_{2.5}$ concentration with abnormal ABI incidence. We performed logistic regression to assess the association between annual average $\mathrm{PM}_{2.5}$ concentration and the incidence of high baPWV. The odds ratio (OR) and its 95\% Confident interval $(\mathrm{CI})$ were calculated. Then restricted cubic spline was used to depict the dose-response relationship and test whether the nonlinear association exists. Multivariate linear regression was conducted to investigate the relationship of annual average $\mathrm{PM}_{2.5}$ concentration with the progression of $\mathrm{ABI}$ and baPWV. We used a step-by-step method to adjust confounding factors in the multivariate models, where the various number of participants were included due to missingness of covariates: (1) crude model $(n=3951)$; (2) model controlling for age and gender ( $\mathrm{n}=3951)$; (3a) model additionally adjusting for BMI, HDL-C, LDL-C, TG, systolic $\mathrm{BP}$, and diabetes $(n=3684)$; (3b) model adjusting for the same set of covariates with model $3 a$ in the same population with model 4 ( $n=1128)$; (4) model additionally controlling for education, smoking, alcohol consumption and physical activity $(\mathrm{n}=1128)$. Model 4 worked as our final model, and its results were mainly reported.

We also conducted subgroup analyses by hypertension status and age group (age $>55$, age $\leq 55$ ) to see which group is more sensitive to an increase in $\mathrm{PM}_{2.5}$ concentration. To test whether the results were robust, we conducted several sensitivity analyses. Multivariate logistic and linear regression was repeatedly conducted with different methods to assess exposure (inverse distance weighted, the nearest monitor method) and different cut-off values to define higher baPWV [27, 28] (1400 $\mathrm{cm} / \mathrm{s}, 1700 \mathrm{~cm} / \mathrm{s}$ ).

Statistical analyses were executed by SAS version 9.3 (SAS Institute, Cary, NC, USA). Two-tailed $P$ values < 0.05 were considered statistically significant.

\section{Results}

The baseline characteristics of study participants are presented in Table 1. The total participants' median age was 56 (IQR: 15) years, and 20.1\% were women. Most participants have attained bachelor's degrees, and more than half of the participants were diagnosed with hypertension. The mean BMI was $25.59 \mathrm{~kg} / \mathrm{m}^{2}$, which fell within the overweight range.

The effect of $\mathrm{PM}_{2.5}$ exposure on the incidence of higher baPWV is depicted in Fig. 1. In the crude model (model 1), $\mathrm{PM}_{2.5}$ was associated with incidence of higher baPWV (OR $=1.17,95 \%$ CI: 1.05-1.31, $P=0.005)$. After

Table 1 Baseline characteristics of the study participants ( $n=$ 1128)

\begin{tabular}{ll}
\hline Characteristic & Distribution \\
\hline annual average $\mathrm{PM}_{2.5}$ concentration $\left(\mu \mathrm{g} / \mathrm{m}^{3}\right)$ median (IQR) & $76.44(6.63)$ \\
Age (year) median (IQR) & $56(15)$ \\
Gender (female) $n(\%)$ & $227(20.12)$ \\
Education $n(\%)$ & \\
Middle school or below & $40(3.55)$ \\
High school & $98(8.69)$ \\
Bachelor's degree & $758(67.20)$ \\
$\quad$ Master's or above & $232(20.57)$ \\
Physical activity $n(\%)$ & \\
Low intensity & $773(68.53)$ \\
Moderate intensity & $262(23.23)$ \\
High intensity & $93(8.24)$ \\
Alcohol consumption $n(\%)$ & $400(35.46)$ \\
Cigarette smoking $n(\%)$ & $302(26.77)$ \\
HDL-C (mmol/L) median (IQR) & $1.24(0.42)$ \\
LDL-C (mmol/L) median (IQR) & $3.03(1.02)$ \\
BMI (kg/m²) mean (SD) & $25.59(3.06)$ \\
TG (mmol/L) median (IQR) & $1.31(0.92)$ \\
Hypertension $n(\%)$ & $566(50.18)$ \\
Diabetes $n(\%)$ & $339(30.05)$ \\
\hline
\end{tabular}

IQR Interquartile range, HDL-C High-density lipoprotein cholesterol, LDL-C Lowdensity lipoprotein cholesterol, $B M I$ Body mass index, SD Standard error, TG Triglyceride 


\begin{tabular}{|llll|}
\hline model & total case & OR (95\% Cl) & P value \\
model 13951 & 363
\end{tabular}

adjusting age and gender (model 2), participants had a $22 \%$ higher risk $(\mathrm{OR}=1.22,95 \% \mathrm{CI}: 1.05-1.41, P=$ 0.010 ) for each increment of $10 \mu \mathrm{g} / \mathrm{m}^{3}$ annual average $\mathrm{PM}_{2.5}$ concentration. The association was still significant in model $3 \mathrm{a}$ after controlling for BMI, HDL-C, LDL-C, $\mathrm{TG}$, systolic $\mathrm{BP}$, and diabetes. However, this association was not significant $(\mathrm{OR}=1.11,95 \% \mathrm{CI}: 0.82-1.50, P=$ 0.497) after further adjusting for education, cigarette smoking, alcohol consumption, and physical activity (model 4). The association was not significant $(P=$ 0.722 ) in model $3 \mathrm{~b}$, which was conducted adjusting for the same set of covariates with model $3 \mathrm{a}$ but in the same population as model 4 . Besides, we noted a small effect estimate reduction from model 4 to models $3 \mathrm{~b}$, but not as large as model 3a, which indicated that model 4 might be mainly influenced by reduced sample size.

A nonlinear curve was observed to associate the annual average $\mathrm{PM}_{2.5}$ concentration with the risk of higher baPWV in the analysis using restricted cubic splines (Fig. 2, $P=0.010$ for the nonlinear test). There was a significant rise in risk with increasing annual average $\mathrm{PM}_{2.5}$ concentrations until the value approached approximately $60 \mu \mathrm{g} / \mathrm{m}^{3}$.

Associations of $\mathrm{PM}_{2.5}$ exposure with a relative annual change of ABI and baPWV are presented in Table 2. The relationship between annual average $\mathrm{PM}_{2.5}$ concentration and $\mathrm{ABI}$ progression was significantly negative in the crude model (model 1) but turned null after adjusting potential confounding factors (model 2-model 4).
However, the effect of annual average $\mathrm{PM}_{2.5}$ concentration on relative annual change of baPWV was always significant from model 1 to model 4 . There was a $1.04 \%$ (95\% CI: $0.72-1.37 \%$ ) gain in baPWV annually with each increment of $10 \mu \mathrm{g} / \mathrm{m}^{3}$ average $\mathrm{PM}_{2.5}$ concentration in the full adjusted model.

Subgroup analyses by age group (age $\leq 55$ and age $>55$ ) showed interesting results (Supplementary Table S2 \& Table S3). The association between the incidence of higher baPWV and $\mathrm{PM}_{2.5}$ exposure was marginally significant $(P=0.056)$ among participants younger than 55 years. Moreover, per $10 \mu \mathrm{g} / \mathrm{m}^{3}$ elevated $\mathrm{PM}_{2.5}$ concentration was associated with a $1.40 \%$ (95\% CI: $0.94-1.86 \%)$ increase in baPWV annually among younger participants. However, this relationship was not observed among older individuals. Several sensitivity analyses were conducted to show that the results were robust (Supplementary Table S4 \& Fig. S1). The estimates did not change apparently when different exposure assessment methods were used. We also applied different cut-off values to define higher baPWV and explored the relationship between the incidence of higher baPWV and $\mathrm{PM}_{2.5}$ exposure. It was worth noting that the association turned significant $(P=0.037)$ with $1700 \mathrm{~cm} / \mathrm{s}$ as the threshold.

\section{Discussion}

In this study, we conducted a longitudinal analysis to investigate the long-term effects of $\mathrm{PM}_{2.5}$ exposure on the progression of $\mathrm{ABI}$ and baPWV. We found a significantly positive association between $\mathrm{PM}_{2.5}$ and baPWV annual change rate in the cohort study but no association between $\mathrm{PM}_{2.5}$ and $\mathrm{ABI}$ annual change rate.

The association between $\mathrm{PM}_{2.5}$ exposure and incidence of higher baPWV was not significant in the final fully adjusted model 4 . Due to the missingness of these covariates, the sample size in model 4 decreased apparently. To explore the reason for effects change, we conducted model $3 \mathrm{~b}$, which adjusted the same covariate with model $3 \mathrm{a}$ in the same population of model 4 . The effects estimated in model $3 \mathrm{~b}$ were similar to those estimated in model 4. It may warn that the confounding effect was small, and a reduced sample size brought false-negative results. Further studies with a larger sample are needed to verify the result.

Our results are partly consistent with previous studies. A study based on the Multi-Ethnic Study of Atherosclerosis cohort failed to find evidence of the relationship between $\mathrm{PM}_{2.5}$ exposure and ABI [14]. A study comprising 4814 men and women found that residential proximity to a major road was associated with $\mathrm{ABI}$, but $\mathrm{PM}_{2.5}$ exposure was not [16]. However, a cross-sectional study [13] using quantile regression revealed a non-monotonic association between $\mathrm{PM}_{2.5}$ exposure and ABI. Simply 


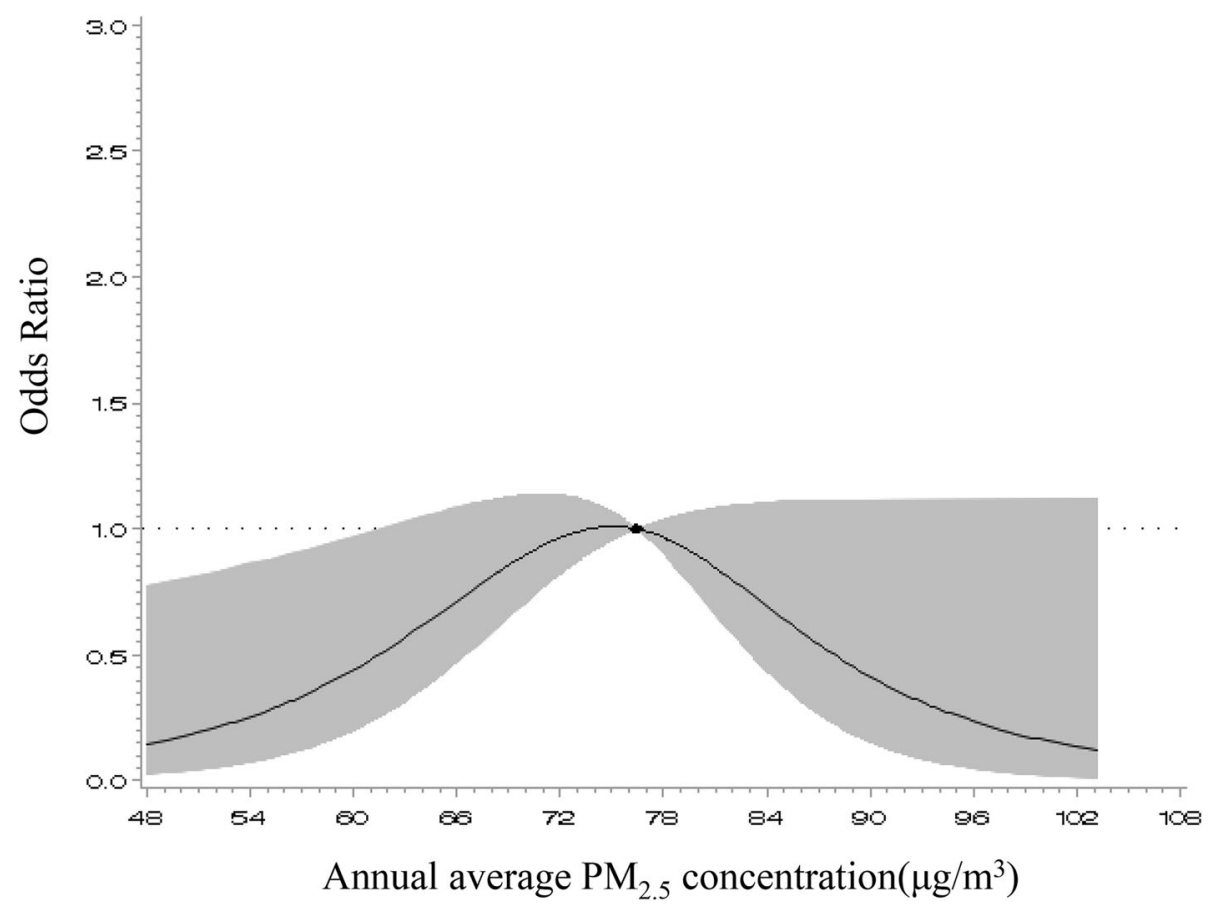

Fig. 2 The relationship between annual average $P_{2.5}$ concentration and incidence of higher baPWV using adjusted restricted cubic spline. The reference value for each $\mathrm{OR}$ is the midpoint of the reference group (i.e., $76.44 \mu \mathrm{g} / \mathrm{m}^{3}$ ). The solid line represented estimated odds ratios and the cloud area indicated $95 \% \mathrm{Cls}$

speaking, participants with relatively low $\mathrm{ABI}$ tended to have an increased risk for lower ABI, but the ones with relatively high $\mathrm{ABI}$ tended to have higher $\mathrm{ABI}$ with increased $\mathrm{PM}_{2.5}$ exposure [13]. A study based on the Framingham Heart cohort did not observe the association between arterial stiffness measures and long-term levels of $\mathrm{PM}_{2.5}$ or short-term levels of $\mathrm{PM}_{2.5}$, where the arterial stiffness was assessed by cfPWV rather than baPWV [6]. However, the short-term effect of $\mathrm{PM}_{2.5}$ on baPWV was observed in a longitudinal study [15].
There are multiple biological mechanisms involved in the association between $\mathrm{PM}_{2.5}$ exposure and arterial stiffness. Inflammation could play a primary role in the process. Animal experiments demonstrated that exposure to $\mathrm{PM}_{2.5}$ intensified plaque progression in mice by inducing vascular inflammation [29]. It is well documented that inflammation could affect functional and structural changes in the arterial wall [30]. Several epidemiological studies [31, 32] also revealed a strong association between inflammatory markers and arterial stiffness. Besides, the effect of exposure to $\mathrm{PM}_{2.5}$ could

Table 2 Association between increased $10 \mu \mathrm{g} / \mathrm{m}^{3} \mathrm{PM}_{2.5}$ concentration and relative annual change of ABI and baPWV

\begin{tabular}{|c|c|c|c|}
\hline Outcome & Model & $\beta(95 \% \mathrm{Cl})$ & $P$ \\
\hline \multirow[t]{5}{*}{ relative annual change of $A B I$} & model 1 & $-0.00177(-0.00312,0.00042)$ & 0.010 \\
\hline & model 2 & $-0.00127(-0.00262,0.00008)$ & 0.065 \\
\hline & model 3a & $-0.00077(-0.00216,0.00061)$ & 0.274 \\
\hline & model 3b & $-0.00166(-0.00438,0.00106)$ & 0.232 \\
\hline & model 4 & $-0.00160(-0.00434,0.00114)$ & 0.252 \\
\hline \multirow[t]{5}{*}{ relative annual change of baPW } & model 1 & $0.00752(0.00592,0.00912)$ & $<0.001$ \\
\hline & model 2 & $0.00736(0.00576,0.00896)$ & $<0.001$ \\
\hline & model 3a & $0.00801(0.00636,0.00966)$ & $<0.001$ \\
\hline & model 3b & $0.01011(0.00688,0.01334)$ & $<0.001$ \\
\hline & model 4 & $0.01044(0.00721,0.01367)$ & $<0.001$ \\
\hline
\end{tabular}

Model 1: crude model; Model 2: additionally adjusted for age and gender; Model 3a: additionally adjusted for BMI, HDL-C, LDL-C, TG, systolic BP, and diabetes; Model 3b: adjusted for the same set of covariates with model 3a in the same population with model 4; Model 4: additionally controlled for education, smoking, alcohol consumption, and physical activity.s 
be mediated through other plausible biologic mechanisms, including blood pressure and autonomic function [33].

According to our knowledge, this is the first study investigating the long-term effects of $\mathrm{PM}_{2.5}$ on the relative change of ABI and baPWV. Most previous studies were limited by only once measurement data. However, this study has several limitations. First, most published studies assessed personal $\mathrm{PM}_{2.5}$ exposure by each participant's residential address rather than the workplace address used in this study. Second, many participants have the same average concentration of $\mathrm{PM}_{2.5}$ exposure (tied data); since enrolled participants in our study were organized by their companies. This might reduce the power of the statistical test. Third, pollution data sources were inconsistent from 2012 to 2018 because $\mathrm{PM}_{2.5}$ pollution data recorded by monitors were not available before 2014. Forth, the potential short-term effect of $\mathrm{PM}_{2.5}$ exposure on arterial stiffness was not adjusted in our analysis.

\section{Conclusions}

In conclusion, there is a significantly positive association of $\mathrm{PM}_{2.5}$ with baPWV annual change rate, but no association between $\mathrm{PM}_{2.5}$ and $\mathrm{ABI}$ annual change rate was found. This study suggests that improvement of air quality may help to prevent arterial stiffness.

\section{Supplementary Information}

The online version contains supplementary material available at https://doi. org/10.1186/s12940-020-00688-6

\footnotetext{
Additional file 1: Table S1. Correlation between data from $\mathrm{PM}_{2.5}$ Hindcast Database and those calculated based on records from monitoring sites from 2014 to 2016. Table S2. Subgroup analysis for the association between increased $10 \mu \mathrm{g} / \mathrm{m}^{3} \mathrm{PM}_{2.5}$ concentration and incidence of higher baPWV. Table S3. Subgroup analysis for the association between increased $10 \mu \mathrm{g} / \mathrm{m}^{3} \mathrm{PM}_{2.5}$ concentration and relative annual change of $A B I$ and baPWV. Table S4. Sensitivity analysis for the association between increased $10 \mu \mathrm{g} / \mathrm{m}^{3} \mathrm{PM}_{2.5}$ concentration and relative annual change of $A B I$ and baPWV. Fig. S1. Sensitivity analysis for the association between increased $10 \mu \mathrm{g} / \mathrm{m}^{3} \mathrm{PM}_{2.5}$ concentration and incidence of higher baPWV. Odds ratios indicated by black boxes were shown along with 95\% confident intervals.
}

\section{Abbreviations \\ ABI: Ankle-brachial index; baPW: Brachial-ankle pulse wave velocity; OR: Odds ratio; BHMC: Beijing Health Management Cohort; BMI: Body mass index; TG: Triglycerides; TC: Total cholesterol; HDL-C: High-density lipoprotein cholesterol; LDL-C: Low-density lipoprotein cholesterol; FPG: Fasting plasma glucose; SD: Standard deviation; IQR: Interquartile range; CFPW: Carotid- femoral pulse-wave velocity}

\section{Acknowledgements}

The authors wish to thank participants of the Beijing Health Management Cohort.

\section{Authors' contributions}

D.S and L.T. designed this study; Y.L. and J.Z. prepared the data; D.S. and J.L. analyzed or interpreted the data; D.S., Z.W., M.L. and L.X. drafted the manuscript. X.G. and L.T. made critical revisions to this paper. The authors read and approved the final manuscript.

\section{Funding}

This research did not receive any specific grant from funding agencies in the public, commercial, or not-for-profit sectors.

\section{Availability of data and materials}

The datasets used and/or analyzed during the current study are available from the corresponding author on reasonable request.

\section{Ethics approval and consent to participate}

All participants provided written informed consent. This study was approved by the Ethics Committees of Capital Medical University (approval number: 2013SY26).

Consent for publication

Not applicable.

\section{Competing interests}

The authors declare that they have no competing interests.

\section{Author details}

${ }^{1}$ School of Public Health, Capital Medical University, Beijing 100069, China. ${ }^{2}$ Beijing Municipal Key Laboratory of Clinical Epidemiology, Beijing 100069, China. ${ }^{3}$ National Cancer Center/National Clinical Research Center for Cancer/ Cancer Hospital, Chinese Academy of Medical Sciences and Peking Union Medical College, Beijing 100021, China. ${ }^{4}$ Department of Mathematics and Statistics, La Trobe University, Melbourne, Australia.

Received: 7 March 2020 Accepted: 18 December 2020

Published online: 06 January 2021

\section{References}

1. Ma Z, Hu X, Sayer AM, Levy R, Zhang Q, Xue Y, et al. Satellite-based spatiotemporal trends in PM2.5 concentrations: China, 2004-2013. Environ Health Perspect. 2016;124(2):184-92.

2. Atkinson RW, Carey IM, Kent AJ, van Staa TP, Anderson HR, Cook DG. Longterm exposure to outdoor air pollution and incidence of cardiovascular diseases. Epidemiology. 2013;24(1):44-53.

3. Pun VC, Kazemiparkouhi F, Manjourides J, Suh HH. Long-term PM2. 5 exposure and respiratory, cancer, and cardiovascular mortality in older US adults. Am J Epidemiol. 2017;186(8):961-9.

4. Cesaroni G, Forastiere F, Stafoggia M, Andersen ZJ, Badaloni C, Beelen R, et al. Long term exposure to ambient air pollution and incidence of acute coronary events: prospective cohort study and meta-analysis in 11 European cohorts from the ESCAPE project. BMJ : Br Med J. 2014;348:f7412.

5. Endes S, Schaffner E, Caviezel S, Dratva J, Stolz D, Schindler C, et al. Is physical activity a modifier of the association between air pollution and arterial stiffness in older adults: the SAPALDIA cohort study. Int J Hyg Environ Health. 2017;220(6):1030-8.

6. Ljungman PLS, Li W, Rice MB, Wilker EH, Schwartz J, Gold DR, et al. Longand short-term air pollution exposure and measures of arterial stiffness in the Framingham heart study. Environ Int. 2018;121(Pt 1):139-47.

7. Zanoli L, Lentini P, Granata A, Gaudio A, Fatuzzo P, Serafino L, et al. A systematic review of arterial stiffness, wave reflection and air pollution. Mol Med Rep. 2017:15(5):3425-9.

8. Vlachopoulos C, Aznaouridis K, Stefanadis C. Prediction of cardiovascular events and all-cause mortality with arterial stiffness: a systematic review and meta-analysis. J Am Coll Cardiol. 2010;55(13):1318-27.

9. Rooke TW, Hirsch AT, Misra S, Sidawy AN, Beckman JA, Findeiss LK, et al. 2011 ACCF/AHA focused update of the guideline for the Management of Patients with peripheral artery disease (updating the 2005 guideline): a report of the American College of Cardiology Foundation/American Heart Association task force on practice guidelines. J Am Coll Cardiol. 2011;58(19): 2020-45.

10. Tanaka H, Munakata M, Kawano Y, Ohishi M, Shoji T, Sugawara J, et al Comparison between carotid-femoral and brachial-ankle pulse wave velocity as measures of arterial stiffness. J Hypertens. 2009;27(10):2022-7. 
11. Laurent S, Cockcroft J, Van Bortel L, Boutouyrie P, Giannattasio C, Hayoz D, et al. Expert consensus document on arterial stiffness: methodological issues and clinical applications. Eur Heart J. 2006;27(21):2588-605.

12. Kim H-L, Kim S-H. Pulse wave velocity in atherosclerosis. Front Cardiovasc Med. 2019;6:41.

13. Zhang S, Wolf K, Breitner S, Kronenberg F, Stafoggia M, Peters A, et al. Longterm effects of air pollution on ankle-brachial index. Environ Int. 2018;118: $17-25$.

14. Diez Roux AV, Auchincloss AH, Franklin TG, Raghunathan T, Barr RG, Kaufman J, et al. Long-term exposure to ambient particulate matter and prevalence of subclinical atherosclerosis in the multi-ethnic study of atherosclerosis. Am J Epidemiol. 2008;167(6):667-75.

15. Wu C-F, Shen F-H, Li Y-R, Tsao T-M, Tsai M-J, Chen C-C, et al. Association of short-term exposure to fine particulate matter and nitrogen dioxide with acute cardiovascular effects. Sci Total Environ. 2016:569-570:300-5.

16. Hoffmann B, Moebus S, Kroger K, Stang A, Mohlenkamp S, Dragano N, et al. Residential exposure to urban air pollution, ankle-brachial index, and peripheral arterial disease. Epidemiology. 2009;20(2):280-8.

17. Jones MR, Diez-Roux AV, O'Neill MS, Guallar E, Sharrett AR, Post W, et al. Ambient air pollution and racial/ethnic differences in carotid intima-media thickness in the multi-ethnic study of atherosclerosis (MESA). J Epidemiol Community Health. 2015;69(12):1191-8.

18. Liu J, Zhao Z, Mu Y, Zou X, Zou D, Zhang J, et al. Gender differences in the association between serum uric acid and Prediabetes: a six-year longitudinal cohort study. Int J Environ Res Public Health. 2018;15(7):1560.

19. Aboyans V, Criqui MH, Abraham P, Allison MA, Creager MA, Diehm C, et al. Measurement and interpretation of the ankle-brachial index: a scientific statement from the American Heart Association. Circulation. 2012;126(24): 2890-909.

20. Takashima N, Turin TC, Matsui K, Rumana N, Nakamura Y, Kadota A, et al. The relationship of brachial-ankle pulse wave velocity to future cardiovascular disease events in the general Japanese population: the Takashima study. J Hum Hypertens. 2014;28(5):323-7.

21. Munakata M. Brachial-ankle pulse wave velocity: background, method, and clinical evidence. Pulse (Basel, Switzerland). 2016;3(3-4):195-204.

22. Guo J, Fujiyoshi A, Masaki K, Vishnu A, Kadota A, Barinas-Mitchell EJ, et al. The role of initial and longitudinal change in blood pressure on progression of arterial stiffness among multiethnic middle-aged men. J Hypertens. 2017; 35(1):111-7

23. Pilz J, Spoeck G. Why do we need and how should we implement Bayesian kriging methods. Stoch Env Res Risk A. 2008;22(5):621-32.

24. Xue T, Zheng Y, Tong D, Zheng B, Li X, Zhu T, et al. Spatiotemporal continuous estimates of PM2.5 concentrations in China, 2000-2016: a machine learning method with inputs from satellites, chemical transport model, and ground observations. Environ Int. 2019;123:345-57.

25. Huang K, Yang X, Liang F, Liu F, Li J, Xiao Q, et al. Long-term exposure to fine particulate matter and hypertension incidence in China. Hypertension. 2019;73(6):1195-201

26. Zhang Z, Guo C, Lau AKH, Chan TC, Chuang YC, Lin C, et al. Long-term exposure to fine particulate matter, blood pressure, and incident hypertension in Taiwanese adults. Environ Health Perspect. 2018;126(1): 017008

27. Zheng X, Zhang R, Liu X, Zhao H, Liu H, Gao J, et al. Association between cumulative exposure to ideal cardiovascular health and arterial stiffness. Atherosclerosis. 2017;260:56-62.

28. Yamashina A, Tomiyama H, Arai T, Hirose K, Koji Y, Hirayama Y, et al. Brachial-ankle pulse wave velocity as a marker of atherosclerotic vascular damage and cardiovascular risk. Hypertens Res. 2003;26(8):615-22.

29. Sun $Q$, Wang A, Jin X, Natanzon A, Duquaine D, Brook RD, et al. Long-term air pollution exposure and acceleration of atherosclerosis and vascular inflammation in an animal model. JAMA. 2005;294(23):3003-10.

30. Jain S, Khera R, Corrales Medina VF, Townsend RR, Chirinos JA. Inflammation and arterial stiffness in humans. Atherosclerosis. 2014;237(2):381-90.

31. Muhammad IF, Borné Y, Östling G, Kennbäck C, Gottsäter M, Persson M, et al. Acute phase proteins as prospective risk markers for arterial stiffness: the Malmö diet and cancer cohort. PLoS One. 2017;12(7):e0181718.

32. Turesson C, Jacobsson L, Rydén Ahlgren A, Sturfelt G, Wollmer P, Länne T. Increased stiffness of the abdominal aorta in women with rheumatoid arthritis. Rheumatology. 2005;44(7):896-901.
33. Donaldson K, Stone V, Seaton A, MacNee W. Ambient particle inhalation and the cardiovascular system: potential mechanisms. Environ Health Perspect. 2001;109(Suppl 4):523-7.

\section{Publisher's Note}

Springer Nature remains neutral with regard to jurisdictional claims in published maps and institutional affiliations.

\section{Ready to submit your research? Choose BMC and benefit from:}

- fast, convenient online submission

- thorough peer review by experienced researchers in your field

- rapid publication on acceptance

- support for research data, including large and complex data types

- gold Open Access which fosters wider collaboration and increased citations

- maximum visibility for your research: over $100 \mathrm{M}$ website views per year

At BMC, research is always in progress.

Learn more biomedcentral.com/submissions 